\title{
Fitting and testing roll-over protective structures on self-propelled agricultural machinery
}

\author{
Domenico Pessina, Davide Facchinetti \\ Dip. di Scienze Agrarie e Ambientali, Università degli Studi, Milan, Italy
}

\section{Abstract}

Roll-0ver Protective Structure (ROPS) represents the state of art for the driver's protection in case of tractors roll-over. Despite their real risk of overturning, the ROPS approach for the Self-Propelled agricultural Machinery (SPM) is quite recent. Due to the several SPM categories available on the market, characterized by very different mass, dimension and working functions, the fitting of a ROPS and consequently the ascertainment of its protection level is quite complicated. SPM could be preliminarily divided into at least two categories:

- large SPM: combine, forage, potato, sugar-beet and grape harvesters; sprayer; etc.;

- $\quad$ small SPM: ride-on tractor, mower, comb side-delivery rake, etc.

The most followed approach at present is to check preliminarily the overturning behavior of the SPM considering its longitudinal and lateral stability; if a real risk of overturning is ascertained, in order to minimize the likelihood of driver's injury the manufacturer often installs a ROPS. The consequent need is to provide some test criteria of them. Sprayers between large SPM, and comb side-delivery rake between small SPM were the machine types on which ROPS were tested, adopting in both cases the procedure provided by Code 4 issued by the Organization for Economic and Cooperation Development (OECD), dedicated to ROPS fitted on conventional agricultural and forestry tractors. Notwithstanding the very different dimensions of these two SPM, this standard was selected considering the predictable roll-over behavior, also in relation with the front and rear track values. On the $4950 \mathrm{~kg}$ mass sprayer was fitted a closed cab, while on the 690 $\mathrm{kg}$ mass comb side-delivery rakes a 3 -pillars frame was applied. In both cases the response of the tests was positive, so indicating a general suitability of OECD Code 4 to assure a ROPS good driver's protection level in case of overturning. On the other hand, to ascertain more in detail the roll-over behavior of the SPM, some further questions need to be deeply examined, such as the driver's place location, the height of the centre of gravity from the ground in different machine configu-

Correspondence: Domenico Pessina, Dip. di Scienze Agrarie e Ambientali, Università degli Stud, Via Celoria, 2, 20133 Milan, italy.

E-mail: domenico.pessina@unimi.it

Key words: self-propelled machinery, stability, roll-over, tip-over, overturning, roll-over protective structure.

@C Copyright D. Pessina and D. Facchinetti., 2013

Licensee PAGEPress, Italy

Journal of Agricultural Engineering 2013; XLIV(s2):e148

doi:10.4081/jae.2013.s2.e148

This article is distributed under the terms of the Creative Commons Attribution Noncommercial License (by-nc 3.0) which permits any noncommercial use, distribution, and reproduction in any medium, provided the original author(s) and source are credited. rations (i.e. with crop tanks empty or full), the external silhouette, the axles mass distribution of the laden/unladen machine, etc.

\section{Introduction}

Beginning from the first experimental trials carried out in Scandinavian countries in early '50 of the last century, the Roll Over Protective Structures (ROPS) to be fitted on agricultural and forestry tractors for the driver's safety in case of roll-over have been considered worldwide the most effective mean against injury occurred in case of overturning (Springfeldt et al., 1998; Reynolds et al., 2000; Guzzomi et al., 2009; Harris et al., 2010; Biddle et al., 2012). Several national and international Standards dealing with ROPS tests were been in the meantime issued, considering progressively the strength test of the protective structures provided for almost all the various agricultural tractor categories: standard (or conventional), tracklaying, narrow track, etc. (Myers, 2000 ; Day et al., 2004 ; Alfaro et al., 2009; Murphy, 2010 ; Arana et al. 2011). Sometimes, further kind of tests were provided, such as those concerning the lateral stability and the non-continuous rolling of the narrow track tractors in case a two pillar front mounted folding roll-bar has to be fitted (Silleli et al., 2009; Guan et al., 2011).

More than 40 years ago, the OECD (Organization of Economic Cooperation Development) started to issue a number of Codes providing procedures to test the ROPS to be fitted on agricultural and forestry tractors, telehandlers used as tractors and other parts and accessories integrating the operator's safety on board in case of overturning, such as the safety belts attachment strength (OECD Codes 4, 6, 7, 8 and 9, 2013).

In recent years, mainly at a national level some rules and guidelines were issued trying to solve the problem of used tractors (Myers, 1995; Freeman, 1999; Franklin et al., 2006), in case they were used and/or introduced again on the market in absence of an international law providing the compulsory fitting of a homologated ROPS.

At present, ROPS on tractors have reached an excellent diffusion, and quite probably this is the most known and popular protection means in case of overturning. In spite of this fact, in Italy more than 130 fatal accidents due to tractor overturning are still occurring every year, mainly due to the use of very old and worn machines, but also because frequently operators working on narrow track tractors keep constantly the folding front roll-bar in the rest position, so nullifying any possible protection of that type of ROPS (Pessina et al., 2009).

In recent years, the accident statistics on agricultural machinery highlighted that not only the tractors can be subjected to a tip- or a rollover, but also some other categories of large Self Propelled Machines (SPM), such as combine harvesters, grape harvesters, sprayers, etc. (Crandall et al., 1997; Day, 1999; Arana et al., 2010) (Figure 1). In these cases, the problem consists of some technical characteristics and working conditions of these SPM, being them as follows: high overall mass, including the content of large tanks fitted on board; high centre of gravity, because the machine is working riding the crop (i.e. grape harvester and sprayer); development of high torque values; travelling on steep and rough slopes at high speed; 
On the other hand, also small SPM, such as ride-on tractors, mowers, comb side-delivery rakes (Figure 2) are subjected to possible roll-over, due in this case not to a large mass or to a high centre of gravity, but rather to the roughness of the ground on which they travel at high speed, leading to skidding and bumps causing the lack of the vehicle control, especially when working on slope during forage management operation.

On the other hand, on small SPM the space reserved to the drive is often very narrow, and also for economical reason no closed cab is fitted, being the seat and the steering-wheel of the machine simply fitted on the main frame. No protection against high and low temperature, rain, wind, dust, noise, vibration, etc. is provided. In case of overturning, the operator on board cannot be protected in any way.

Because for both large and small SPM the overturning is a real hazard, their risk evaluation must consider the means to avoid or at least minimize this kind of hazard. Manufacturers have studied some systems to increase the stability of these machines, and also some international standards, such as EN 16231, provide a similar approach, taking into account the preliminary measurement of the static lateral and longitudinal stability of a given machine, thus comparing the limit angle values found with the limits established for the category in which the machine is included. If the stability does not satisfy the requirement, the manufacturer must consider the fitting of means able to reduce the driver's injury in case of overturning.

Thanks to the very long and deep expertise accumulated in more than 50 years for the similar question regarding the agricultural and forestry tractors, the manufacturers consider as a priority the fitting of a ROPS. On the large SPM, a suitable reinforcement of the cabs already fitted has to be provided. As an alternative, sometime a very stiff 2-pillars roll-bar or a 4-pillars frame is added to the original cab. Diversely, a simple 2,3 or 4 pillars simple frame is applied to the small SPM.

Of course, these ROPS have to be tested, in order to ascertain if they are sufficiently strong to assure a suitable volume around the driver's place in case of overturning. At present, no dedicated Standards are available, and therefore those used normally for the ROPS to be fitted on agricultural and forestry tractors are considered.

\section{The SPS (Self-Protective Structure)}

On the other hand, the location of the driver's place on the tractors compared with that of SPM is often quite different: on the conventional tractors the seat and the steering wheel are normally located in a central-rear position, being them also central considering the lateral axis, lying on the longitudinal centre line. On the contrary, on the SPM the driver's place is often located in extreme front of rear positions and sometime is not central in the lateral axis.
Moreover, especially for large SPM the so called Self-Protective Structures (SPS) have to be considered for an extra protection in case of overturning. As defined in ISO 16231-1, the SPS are structural components of the machine with sufficient strength to provide a deflection limiting volume if the machine overturns.

The SPS can be represented by tanks, frames, shields, carters, etc. normally fitted on the machine, providing a certain energy absorption in case of overturning, avoiding partially (or sometime completely) the mechanical stress to which the cab structure should be subjected. Thus, the mechanical features of these structural elements have to be defined by adopting one (or more) testing method(s), allowing to identify and assess their strength in a reliable and repeatable way.

This is not a new principle, because in some standards dedicated to the testing of the ROPS to be fitted on earth-moving machinery (such as ISO 12117-2:2008/Cor 1:2010 "Earth-moving machinery Laboratory tests and performance requirements for protective structures of excavators Part 2: Roll-over protective structures (ROPS) for excavators of over $6 t$ ") some simulated ground planes are defined. Each of them is ascertained by at least 3 stiff points located on the machine (deriving from
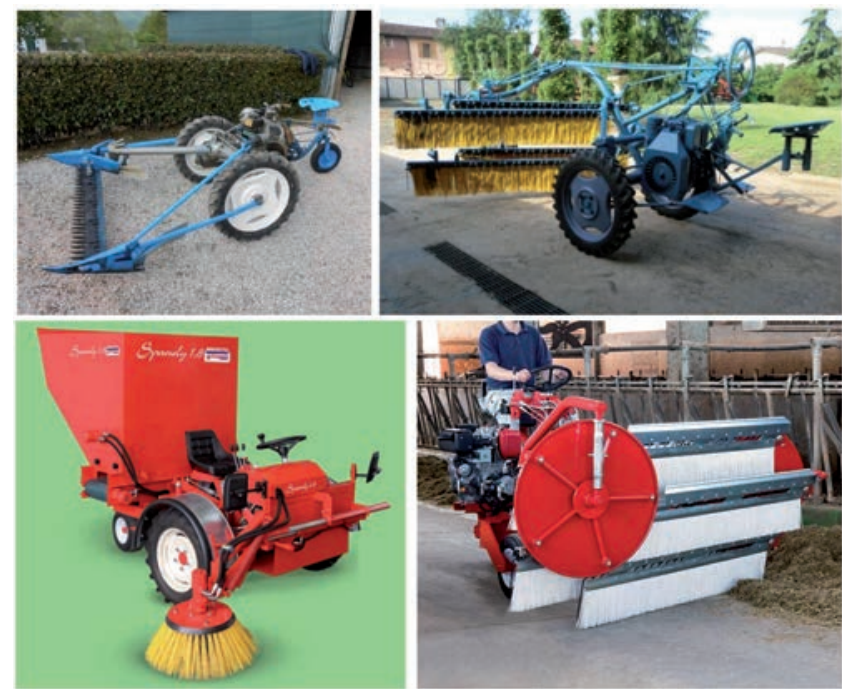

Figure 2. Some examples of small SPM. From left to right and from top to bottom: a self-propelled mower, a side-comb delivery rake, a multifunctional machine to clean the berth edge and a motor brush.
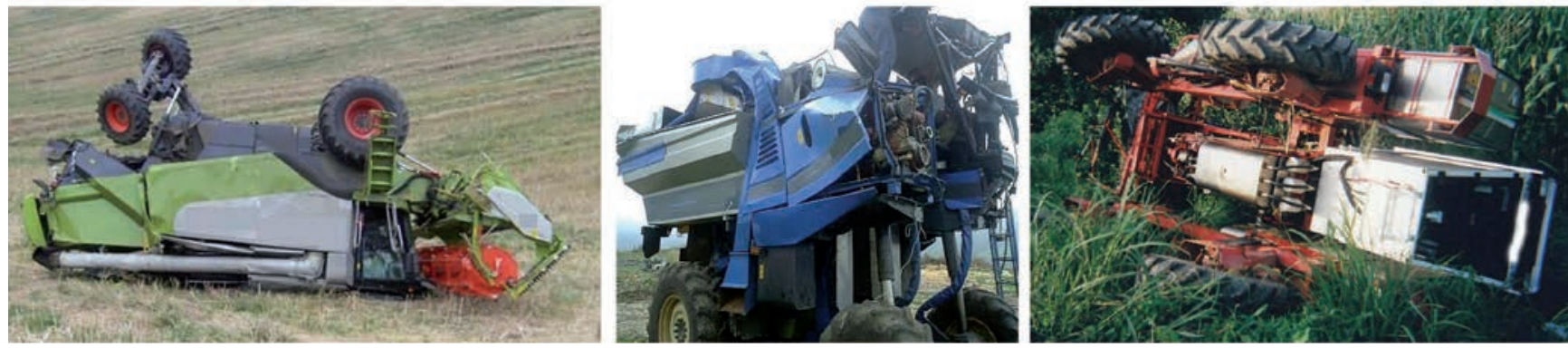

Figure 1. Some categories of large SPM, such as combine harvesters, grape harvesters and sprayers are subjected to tip- and roll-over due to their technical characteristics and working conditions (courtesy of INAIL - Rome, Italy). 
SPS), which can provide protection for the operator in case of impact with the ground during a machine tip- or roll-over. In case the operator seat is off the machine longitudinal centre line, the worst condition has to be considered. Thus, a lateral, front, rear and upper boundary simulated ground planes (named respectively LBSGP, FBSGP, RBSGP and UBSGP, Figure 3) can be defined (INAIL, Rome-Italy, 2013).

The stiff points are lying on rigid structural members that remain fixed and unchanged on the machine in any configuration (including working on field and transport conditions), showing adequate strength to support the induced loads during a tip- or roll-over resulting in predictable deformation. Shall not be considered as stiff points interchangeable or detachable devices, e.g. for combine harvesters the header or the pick-up and stripping heads, and for grape harvesters detachable vine shoot tipping devices.
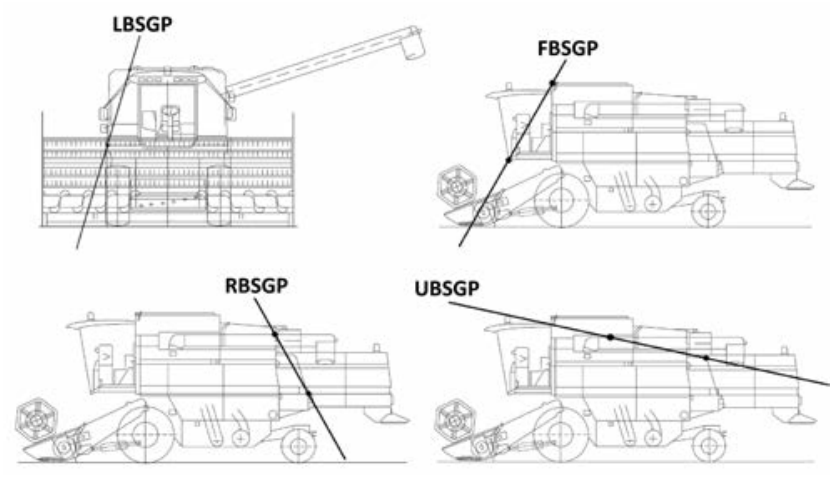

Figure 3. Example of lateral (LBSGP), front (FBSGP), rear (RBSGP)and upper (UBSGP) boundary simulated ground planes, referred to a combine harvester (courtesy of INAIL - Rome, Italy).
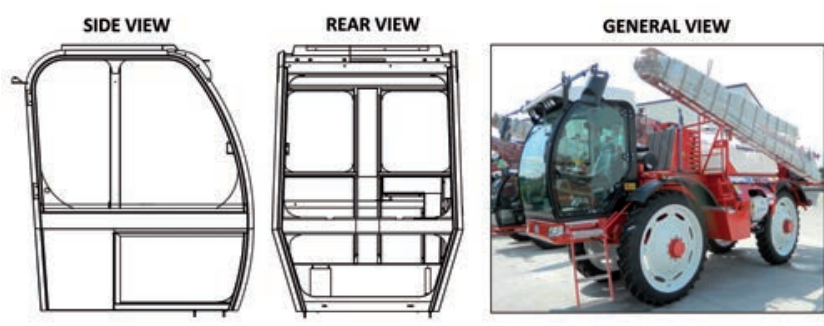

Figure 4. General drawings and view of the ROPS fitted on the large SPM, a self-propelled sprayer.

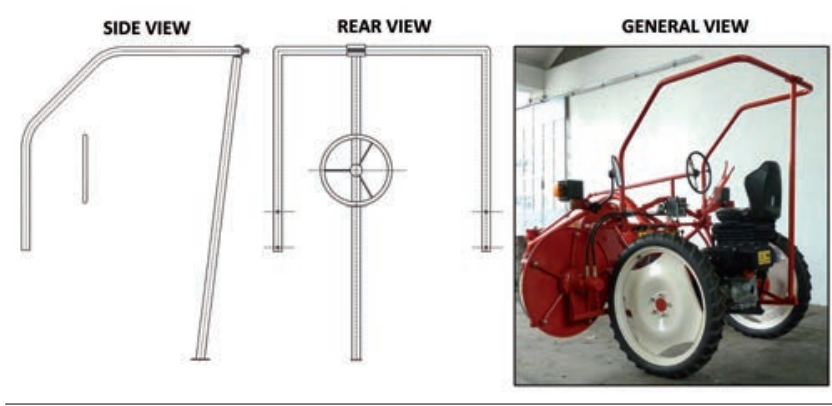

Figure 5. General drawings and view of the ROPS fitted on the small SPM, a comb side-delivery rake.
Some procedures have been proposed in order to test physically the strength of the stiff points. One of them provides to apply a static force equal to $2 / 3$ of the machine weight in a perpendicular direction to the ground when the given point touches the terrain in case of overturning. In any case, with reference to the rigs at present available for the ROPS tests, considering the remarkable overall dimensions of the large SPM the execution of such tests could be very difficult and sometime really impossible. As an alternative, a virtual test (a computerized simulation) carried out by using the FEA method (Finite Element Analysis) could be profitably used (Karlinsky et al., 2013). In fact, by now this kind of software has assured a high level of affordability and a reduced deviation of the output data in respect to the results of the real test.

\section{Materials and methods}

Waiting for the definite issue of Standards specifically dedicated to the large SPM (such as ISO 16231) and to the small ones, manufacturers asked with urgency for the testing of ROPS to be fitted on SPM, being it the most common (and quick) solution considered for the protection of the driver in case of tip- or roll-over. In the first instance, the lack of dedicated Standards leads to the application of those already used for similar machinery, mainly agricultural and forestry tractors, and sometime also earth-moving machines. On the subject, the OECD Code 4 appears at present the most known and applied standard. For this reason, two tests were carried out, respectively on the ROPS fitted on a self-propelled sprayer (large SPM), and on a comb side-delivery rake (small SPM). The most important technical characteristics of these two SPM (mainly their mass and front and rear track values) were into the range provided for the application of the OECD Code 4.

In detail, on the self-propelled sprayer a 4-pillars closed cab was fitted; on the contrary, due to technical and economical reasons, a simple 3-pillars frame was provided for the comb side-delivery rake (Figs. 4 and 5).

The OECD Code 4 provides a sequence of 4 tests, by absorbing defined energies ( $\mathrm{E}$, in $\mathrm{J}$ ) or applying defined forces (F, in $\mathrm{N}$ ) depending them on the machine mass ( $\mathrm{M}$, in $\mathrm{kg}$ ), as shown in Table 1.

The machine mass appears a key feature on which are based the energies to be absorbed and the forces to be applied. Similarly, on SPM that are not harvesting of distributing material is easy to define a reference mass to calculate energy and force values, but for example the cases of combine and grape harvesters and also the self-propelled sprayers are more complicated, due to large mass variation occurring in the conditions of $\operatorname{tank}(\mathrm{s})$ empty or full. In such cases, the mass can double or more. Moreover, the tanks can be open or closed: in the first case, in the event of an overturning, all (or part) of the material could escape outside, thus decreasing the mass of the machine and the stress on its structure when touching the ground. On the other hand, no mass variation could occur in case of closed tank(s), but attention should be paid to the attachment of the $\operatorname{tank}(\mathrm{s})$, considering a possible complete

Table 1. Tests sequence and formulae used in OECD Code 4 for testing ROPS to be fitted on agricultural and forestry tractors.

\begin{tabular}{lcc} 
Test sequence & Loading & Formula \\
1 & Rear horizontal & $\mathrm{E}=1.4 \mathrm{M}$ \\
2 & Rear vertical & $\mathrm{F}=20 \mathrm{M}$ \\
\hline 3 & Side horizontal & $\mathrm{E}=1.75 \mathrm{M}$ \\
4 & Front vertical & $\mathrm{F}=20 \mathrm{M}$
\end{tabular}


detachment from the machine frame.

In Table 2 the main technical characteristics of the two SPM are shown, as far as the energies to be absorbed and the forces to be applied.

\section{Results and discussion}

Because cabs and frames are normally manufactured with vertical pillars, in the major part of the ROPS tests the horizontal loadings (to the rear and to the side in the case of OECD Code 4) result more severe rather than those applied vertically. The reason is that in the vertical direction the pillars are loaded in a buckling, while the horizontal tests load the structural components in their weakest section. Also in the two tests of ROPS fitted on SPM this condition has been verified, and as a consequence only the horizontal loadings have been investigated.

In Figs. 6 and 7 are shown the Force-Deflection (F-D) curves and the view at the end of the rear and side loadings of the ROPS fitted on the two SPM considered. On the F-D curves, also the values of permanent and elastic deflection were calculated, comparing them with the total deflection value.

In general, a ROPS is absorbing the energy provided by the formulae in the stress-strain field, so resulting a certain amount of both plastic (permanent) and elastic (temporary) deflection.

At the same time, the need to maintain protected the clearance zone (representing the presumable volume occupied by the driver properly attached to the seat when the machine overturns), as well as to limit at a reasonable size the ROPS, often constrains the designer to a compro- mise between the possibility to absorb energy in terms of both plastic and elastic deflection. In practice, a well designed ROPS shows a ratio plastic/elastic deflection ranging between 0.66 and 1.50. In other words, both the plastic and elastic deflection values range normally between $40 \%$ and $60 \%$ of the total.

As a consequence, a plastic deflection value higher than $60 \%$ of the total (and consequently an elastic deflection less than 40\%) is typical of a very stiff ROPS, sometime fitted on narrow machines, where the deflection of the pillars has to be quite low, because the structure members must not enter into the safety zone. On the contrary, on large machines the possibility to fit "elastic" ROPS is higher, due to their largest overall dimensions.

The Plastic (PD) and Elastic (ED) Deflection values recorded for the tests of the ROPS fitted on the self-propelled sprayer confirmed this principle, being respectively $59 \%-41 \%$ (ratio PD/ED $=1.44$ ) for the rear loading, and $46 \%-54 \%$ (ratio PD/ED = 0.85) for the side loading. On the other hand, the ROPS type fitted was a closed cab made in the majority of its parts with shaped welded steel sheet and tubes. Different values were on the contrary recorded for the ROPS fitted on the comb sidedelivery rake, being for the rear and side loadings respectively $39 \%-61 \%$ (ratio $\mathrm{PD} / \mathrm{ED}=0.64$ ) and $36 \%-64 \%$ (ratio $\mathrm{PD} / \mathrm{ED}=0.56$ ). In this case, for both loadings the ROPS revealed a poor plasticity, and consequently a very high elasticity. This was because the ROPS was a quite simple frame, manufactured with welded rounded tubes; at the same time, there was no criticism regarding the overall dimensions of the ROPS, having the machine a remarkable wheelbase and track values if compared with its low mass. Moreover, the frame was based on 3 pillars, a very unusual asymmetric design solution, considering that frames and roll-bars fitted normally on agricultural tractors have 2 or 4 pillars.

Table 2. Minimum values of energy to be absorbed and force to be applied to the ROPS fitted on the two SPM..

\begin{tabular}{lccc} 
Loading & Formula & $\begin{array}{c}\text { Self-propelled sprayer } \\
\text { (Mref }=4950 \mathrm{~kg} ; \\
\text { min track }=1800 \mathrm{~mm} \\
\text { wheelbase }=2820 \mathrm{~mm})\end{array}$ & $\begin{array}{c}\text { Comb side-delivery rake } \\
\text { (Mref }=690 \mathrm{~kg} \\
\text { min track }=1340 \mathrm{~mm} \\
\text { wheelbase }=2440 \mathrm{~mm})\end{array}$ \\
Rear horizontal & $\mathrm{E}=1.4 \mathrm{M}$ & $\mathrm{E}=6.93 \mathrm{~kJ}$ & $\mathrm{E}=0.97 \mathrm{~kJ}$ \\
Rear vertical & $\mathrm{F}=20 \mathrm{M}$ & $\mathrm{F}=99.0 \mathrm{kN}$ & $\mathrm{F}=13.8 \mathrm{kN}$ \\
\hline Side horizontal & $\mathrm{E}=1.75 \mathrm{M}$ & $\mathrm{E}=8.66 \mathrm{~kJ}$ & $\mathrm{E}=1.21 \mathrm{~kJ}$ \\
Front vertical & $\mathrm{F}=20 \mathrm{M}$ & $\mathrm{F}=99.0 \mathrm{kN}$ & $\mathrm{F}=13.8 \mathrm{kN}$ \\
\hline
\end{tabular}
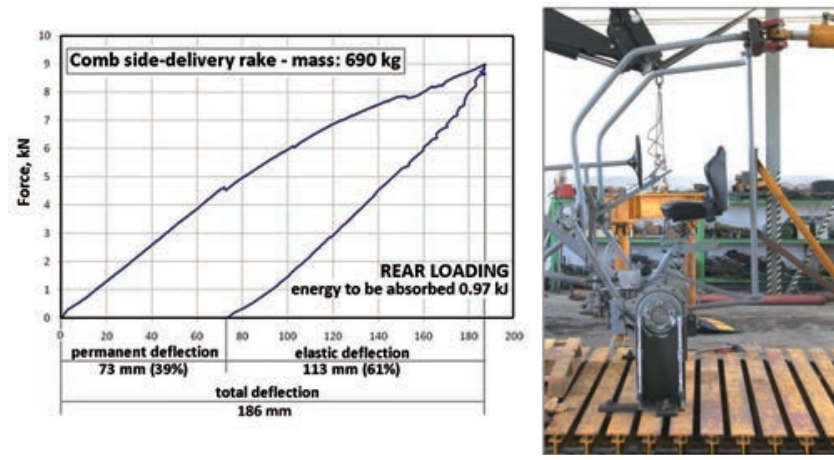

Figure 6. Force-deflection curves and condition at the end of the rear and side loadings of the ROPS fitted on the self-propelled sprayer.
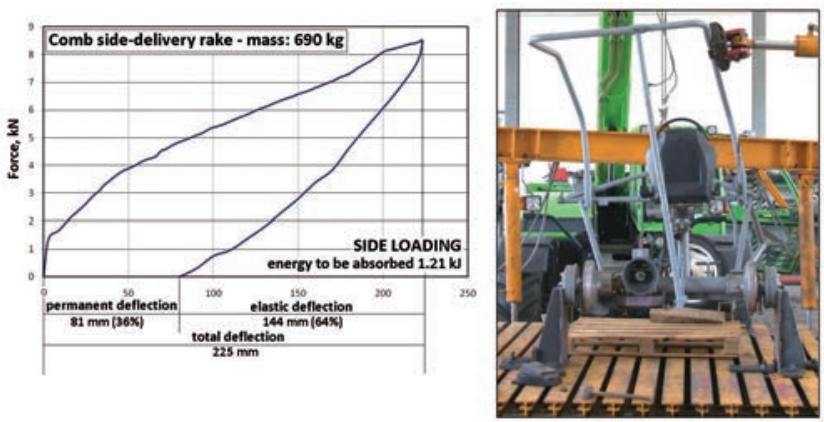

Figure 7. Force-deflection curves and condition at the end of the rear and side loadings of the ROPS fitted on the comb side-delivery rake. 
In Figs. 8 and 9 the final permanent deflections of the two ROPS are shown, resulting from the sequence of the 4 loadings. As expected, for both ROPS no high deflection occurred in the vertical plane, having recoded values ranging between $5 \mathrm{~mm}$ and $45 \mathrm{~mm}$. This happens because this kind of structures show a remarkable stiffness being the force applied in the direction of their maximum resistance.

On the contrary, in the horizontal plane the behavior of the two ROPS was different. In the longitudinal direction (from back forwards), for the cab fitted on the self-propelled sprayer the permanent deflection was logically higher on the side where the loading was applied, while for the comb side-delivery rake the values of the left and right sides were similar, because the frame fitted had just one pillar at its back, more or less in the central position of the structure. Moreover, in this last case the deflection recorded was higher, due to the remarkable elasticity of this ROPS in comparison with the other.

Also the deflection values resulting in the lateral direction were noticeable, due to the high energy to be absorbed in the side loading, which is the most severe in the entire sequence of tests. The cab fitted on the self-propelled sprayer showed a higher deflection in its rear part, while the frame of the comb side-delivery rake highlighted the same deflection in the front and rear parts.

For both structures, the acceptance conditions of the tests carried

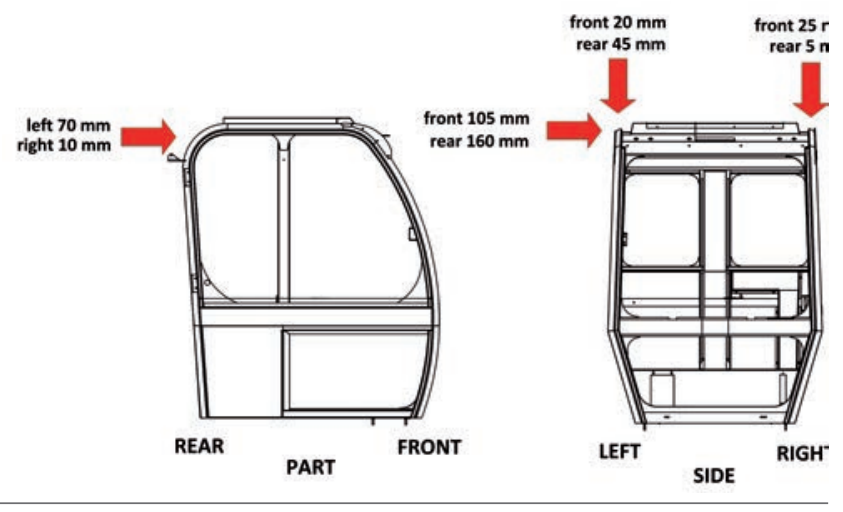

Figure 8. Permanent deflection values of the ROPS fitted on the self-propelled sprayer, resulting after the sequence of the 4 loadings provided by OECD Code 4.

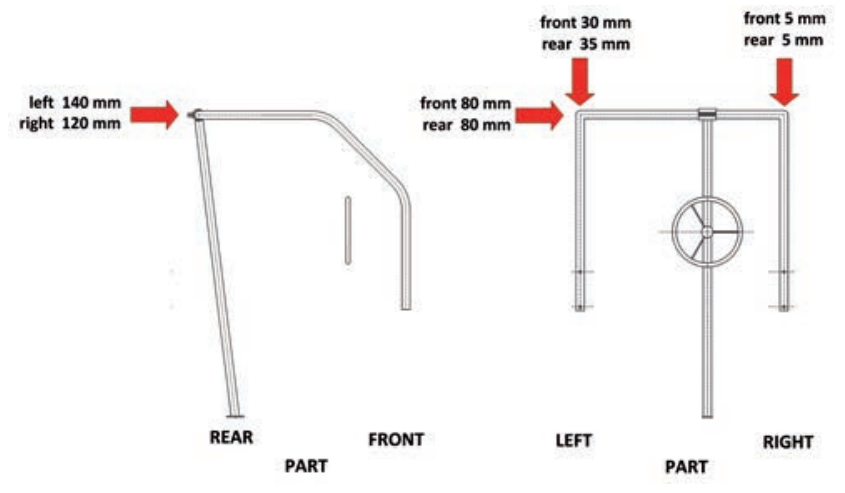

Figure 9. Permanent deflection values of the ROPS fitted on the comb side-delivery rake, resulting after the sequence of the 4 loadings provided by OECD Code 4. out relative to the protection of the clearance zone were fulfilled. Thus, the two structures can be considered a roll-over protective structure in accordance with the OECD Code 4. On the other hand, the two SPM were not critical for their overall dimensions. The respect of the clearance zone could be difficult on other narrow SPM, such as self-propelled mower or some multifunctional machines used in the livestock breeding, such as for example that to clean the berth edge.

\section{Conclusions}

On the SPM, the protection of the driver in case of overturning (and also that of a possible passenger on board) is still suffering for a lack of dedicated standards. The ISO 16231 is dealing with this question: the approach considered is quite interesting and well promising to solve the problem.

On the other hand, if the fitting of a ROPS is the solution selected by manufacturers to increase the driver's safety in case of overturning, the actual standards developed for agricultural and forestry tractors appear adequate for some categories of large SPM, such as some selfpropelled sprayers, but not for several other categories (e.g. combine and grape harvesters), where the driver's place is located in the front part of the machine and sometime on one of the two sides.

The existing Self-Protective Structure (SPS) may modify remarkably the overturning dynamics of the SPM, depending on the stiffness of their points and the definition of the various boundary simulated ground planes. In some cases SPS could represent important means to reduce the mechanical stress of the cab, but in other situations could play a negative role just due to their stiffness, forcing the cab structure to absorb the great part of the energy developed in tip- or roll-over. This is for example the typical condition in case of front-side overturning when the driver's place is located in the front part of the machine.

The ISO 16231 primarily consider the stability of each SPM, and consequently the level of its risk of overturning. Only if the longitudinal and lateral stability values are lower than the limits established, the manufacturer is compelled to provide other means to reduce the risk. Very often the solution of fitting a ROPS is selected, due to the wide experience accumulated on agricultural and forestry tractors. Thus, the accurate and careful definition of the limit stability angles for each SPM category will have a great importance: several studies are in progress, devoted to evaluate the situation on the models currently on the market.

To come to a suitable solution of the general problem, the development of a series of specific standards for the testing of the ROPS designed to be fitted on SPM will be probably needed, considering that several both large and small SPM differ remarkably in design and function from the agricultural and forestry tractors.

\section{References}

Alfaro JR, Arana I, Arazuri S, Jaren C. Assessing the safety provided by SAE J2194 Standard and Code 4 Standard code for testing ROPS, using finite element analysis Biosystems Eng. 2010; 105(2):189-97.

Arana JI, Mangado J, Arnal P, et al. Evaluation of risk factors in fatal accidents in agriculture. Spanish Journal of Agricultural Research, 2010; 8(3):592-8.

Arana JI, Alfaro JR, Arazuri S, et al. A proposal to improve the sae standard and OECD code 4 standard code for testing ROPS. Transactions of the ASABE 2011, 54(4): 1189-97.

Biddle EA, Keane PR. Action Learning: A New Method to Increase 
Tractor Roll-over Protective Structure (ROPS) Adoption. Journal of Agromedicine 2012; 17(4):398-409.

Crandall CS, Fullerton L, Olson L, et al. Farm-related injury mortality in New Mexico, 1980-91. Accid Anal Prev. 1997; 29(2):257-61.

Day LM Farm work related fatalities among adults in Victoria, Australia. The human cost of agriculture. Accident Analysis and Prevention $1999 ; 31: 153-9$.

Day LM, Rechnitzer G, Lough J. An Australian experience with tractor roll-over protective structure rebate programs: process, impact and outcome evaluation. Accid Anal Prev. 2004; 36(5):861-7.

Franklin RC, Stark K, Fragar L. Intervention strategies for the retro-fitment of Roll-over Protective Structures (ROPS) and fleet characteristic, farm tractors. Safety Science 2006; 44:771-83.

Freeman SA. Potential impact of a ROPS retrofit policy in central Iowa. J Agric Saf Health 1999; 5:11-20.

Guan J, Hsiao H, Zwiener JV, et al. Evaluating the protective capacity of two-post ROPS for a seat-belted occupant during a farm tractor overturn. Journal of Agricultural Safety and Health, 2011; 17(1):1532.

Guzzomi AL, Rondelli V, Guarnieri A, et al. Available energy during the roll-over of narrow-track wheeled agricultural tractors. Biosystems Engineering 2009; 104:318-23.

Harris JR, McKenzie EA, Etherton JR, et al. ROPS performance during field upset and static testing. J. Agric. Safety and Health 2010; 16(1):5-18.

Karlinski J, Ptak M, Działak P. Simulation tests of roll-over protection structure. Archives of civil and mechanical engineering 2013 13:5 7-63.

Murphy D, Myers J, McKenzie Jr, et al. Tractors and roll-over protection in the United States. J Agromedicine 2010; 15:249-63.

Myers JR, Snyder KA. Roll-over protective structure use and the cost of retrofitting tractors in the United States, 1993. J Agric Saf Health 1995; 1:185-197.
Myers ML. Prevention effectiveness of roll-over protective structures, Part I: Strategy evolution. Journal of Agricultural Safety and Health 2000; 6(1):29-40.

Pessina D, Facchinetti D. Il ruolo del web nel monitoraggio degli incidenti mortali dovuti a ribaltamento nei trattori agricoli. Proc. of "Il nuovo Testo Unico e la sicurezza nel settore agroforestale", Viterbo (Italy), 2009, 1-18.

Reynolds SJ, Groves W. Effectiveness of roll-over protective structures in reducing farm tractor fatalities. American J. Prev. Med. 2000; 18(4S):63-9.

Silleli H, Ta ba H, Çay CI. A research on the evaluation of front hard point part of agricultural and forestry tractors. Tarim Bilimleri Dergisi 2009; 15(2):166-72.

Springfeldt B, Thorson J, Lee BC. Sweden's thirty-year experience with tractor roll-overs. J Agric Saf Health 1998; 4:173-80.

INAIL (Istituto Nazionale per l'Assicurazione contro gli Infortuni su Lavoro) "Self Protective Structure (SPS) and Roll Over Protective Structure (ROPS) for agricultural self-propelled machines", Rome (Italy), 2013.

ISO (International Organization for Standardization) "Earth-moving machinery Laboratory tests and performance requirements for protective structures of excavators Part 2: Roll-over protective structures (ROPS) for excavators of over 6 t. Norm ISO 121172:2008/Cor 1:2010, Geneva: International Organization for Standardization Publications; 2010.

IS0 (International Organization for Standardization) "Self-propelled agricultural machinery. Assessment of stability. Norm ISO 16231 Parts 1 and 2-2013, Geneva: International Organization for Standardization Publications; 2013.

OECD Codes 4, 6, 7, 8 and 9 (2013). OECD Standard Code for the Official Testing of Roll-over Protective Structures on Agricultural and Forestry Tractors. Organisation for the Economic Co-operation and Development, Paris, France. 